\title{
X-Ray Radiography of Fracture Flow and Matrix Imbibition in Topopah Spring Tuff Under a Thermal Gradient
}

\author{
Jeffery J. Roberts \\ Wunan Lin
}

This paper was prepared for submittal to the NYRocks '97, 36th U.S. Rock Mechanics Symposium

New York, NY

June 29-July 2, 1997

This is a preprint of a paper intended for publication in a journal or proceedings. Since changes may be made before publication, this preprint is made available with the understanding that it will not be cited or reproduced without the permission of the author. 


\section{DISCLAIMER}

This document was prepared as an account of work sponsored by an agency of the United States Government. Neither the United States Government nor the University of California nor any of their employees, makes any warranty, express or implied, or assumes any legal liability or responsibility for the accuracy, completeness, or usefulness of any information, apparatus, product, or process

disclosed, or represents that its use would not infringe privately owned rights. Reference herein to any specific commercial product, process, or service by trade name, trademark, manufacturer, or otherwise, does not necessarily constitute or imply its endorsement, recommendation, or favoring by the United States Government or the University of California. The views and opinions of authors expressed herein do not necessarily state or reflect those of the United States Government or the University of California, and shall not be used for advertising or product endorsement purposes. 


\title{
X-RAY RADIOGRAPHY OF FRACTURE FLOW AND MATRIX IMBIBITION IN TOPOPAH SPRING TUFF UNDER A THERMAL GRADIENT
}

\author{
Jeffery J. Roberts and Wunan Lin \\ Lawrence Livermore National Laboratory \\ PO Box 808, L-201, Livermore, CA 94551 USA
}

\begin{abstract}
A method of imaging the flow of liquid in fractures and matrix imbibition in tuff using x-ray radiography has been developed and a formulation for the calculation of saturation in the matrix based on x-ray radiography is presented. Experiments were performed using different thermal gradients and hydrostatic heads. The distance that liquid penetrates the boiling region was found to be dependent on hydrostatic head: during the highest-head experiment, liquid water penetrated the entire fracture and continued to pass through the boiling region. For experiments where flow stopped at the boiling region, x-ray images indicate crystal deposition along the fracture. In some cases, when the sample was cooled, fracture flow resumed, and in other cases the fractures were sealed and flow did not continue.
\end{abstract}

\section{KEYWORDS}

Fracture flow, Fluid flow, Temperature effects, Rock properties, Radioactive waste, Laboratory tests, Transport properties, Permeability

\section{INTRODUCTION}

Understanding and predicting the performance of a high-level nuclear waste repository requires knowledge of how water flows through heated, unsaturated, fractured rock. Several strategies and models for the isolation of waste packages and containment vessels from infiltrating liquid water and condensate from steam have been proposed (e.g. Buscheck and Nitao, 1992). These strategies depend to some degree on flow in fractures under thermal gradients and the effect of matrix imbibition on fracture flow (Wilder, 1996). The distance that water can travel during gravity driven fracture flow is controlled by several factors, including the saturation of the matrix, the fracture aperture, the capillary properties of the matrix, and the temperature of the rock (Nitao and Buscheck, 1991). Flow in fractures is potentially slowed by imbibition into the matrix that is driven by capillary suction. A theoretical investigation of liquid flow and infiltration into heated rock has been reported by Phillips (1994 and 1996). Phillips shows that the depth of penetration of liquid fingers into superheated rock is dependent on several factors including flux, thermal conductivity of the rock mass and the temperature gradient. In the present work, a series of experiments has been performed to investigate fracture flow and fracture-matrix interactions under a thermal gradient using x-ray radiography to image some of the above factors and processes. 


\section{EXPERIMENTAL METHODS}

Tabular blocks (23 x 15 x $2.6 \mathrm{~cm}$ ) of densely welded Topopah Spring tuff were prepared from outcrop samples from Fran Ridge, NTS. The matrix porosity as determined by mercury injection and by gravimetric methods was $\sim 10 \%$. Tensile fractures were induced in the middle of the samples, oriented so that the plane of the fracture was parallel to the direction of x-ray transmission, which is parallel to the smallest dimension (Figure 1). These fractures were held open with $0.5 \mathrm{~cm} \times 1 \mathrm{~cm} \times 25 \mu \mathrm{m}$ thick gold shims evenly spaced along the fracture in order to control the fracture aperture. These shims show up as highly attenuating lines in the normal radiographs (Figure 2).

Samples were coated with a silicon moisture barrier on all vertical sides, and mounted in an aluminum frame. At the top and bottom of the sample were chambers for ponding and collection of water. Three heaters were mounted on an aluminum plate in thermal contact with the bottom of the sample. Channels were machined in the aluminum plate to enable water flowing the length of the fracture to exit the sample to a lower collection chamber. Each heater had a separate power supply so that by varying the power to each heater an even temperature distribution could be achieved. Thermocouples (Type J) were placed near the heaters, on top of the rock near the fracture, and inserted into the rock to monitor temperature. The thermocouples placed in the rock entered the sample from the side, out of the way of the detector, and penetrated a distance of $3.8 \mathrm{~cm}(\sim 3.7 \mathrm{~cm}$ from the fracture). Two experiments will be described here: FR5 and FR6 (Table 1). The difference between these two experiments is that FR6 had four additional heaters on the sides of the sample. This was done to create a lower temperature gradient from the top to the bottom of the sample. FR5 had a temperature of $\sim 111^{\circ} \mathrm{C}$ at the bottom and $\sim 28^{\circ} \mathrm{C}$ at the top, and FR6 had a temperature $\sim 148^{\circ} \mathrm{C}$ at the bottom and $\sim 80^{\circ} \mathrm{C}$ at the top. The boiling region $\left(\mathrm{T}>100^{\circ} \mathrm{C}\right.$ ) extended 2 to $3 \mathrm{~cm}$ into FR5 (from the bottom) while FR6 had a much larger boiling region extending 6-7 cm into the sample (from the bottom). Two experiments were performed on FR6, one with a hydrostatic head of $\sim 0.26 \mathrm{~m}$, and another with the head approximately $0.46 \mathrm{~m}$. The head on FR5 was quite small, only 1-2 cm, which was the chamber height where the water ponded on top of the sample. Note that the measurement of head is not exact because of the translation of the stage and the lack of a large reservoir at the top of the water column. A calibrated burette was used to measure the amount of water that entered the sample. Between radiographs, water level readings were taken and the burette filled as needed. After the first experiment on FR6, distilled water was permitted to flow the length of the fracture in an attempt to eliminate any KI crystals that may have been deposited during the previous boiling event. The second experiment was performed in an attempt to test the effect of head on penetration of liquid into the boiling region.

$\mathrm{X}$-ray radiographs were taken periodically to image water movement into the fracture and rock matrix by translating the sample vertically through a $160 \mathrm{kVp}$ linear x-ray source (tungsten target and a $41 \mu \mathrm{m} \mathrm{Cu}$ filter). X-rays passing through the sample were converted to a digital signal by a photo-diode linear array detector and stored by computer. Water (doped with KI to enhance contrast, $10 \%$ by weight) was ponded on the top of the upper fracture surface and allowed to flow down the fracture while $\mathrm{x}$-ray radiographs were periodically taken to image water movement in the fracture and matrix. For these two sets of experiments, water entered the sample only through the top fracture area (the rest of the sample tops were sealed). X-ray images were generally analyzed in two different ways, by simple difference imaging and by saturation calculation (vida infra). The difference image method consists of taking background radiographs of the sample in an initial known state (typically dry or fully saturated). After imposing some change on the sample such as liquid flow, or heating or cooling, changes from the initial state can be observed by subtracting the initial image from the subsequent images. Difference imaging permits the qualitative imaging of spatial and temporal variations of saturation in the matrix. More quantitative evaluations of saturation are performed by a similar procedure described below. Most flow and imbibition phenomena and processes can be observed through difference imaging.

TABLE 1

EXPERIMENTAL PARAMETERS

\begin{tabular}{|l||l|c|c|c|}
\hline Sample/Run & Number of Heaters & Bottom Temp., C & Top Temp., C & Water Column Height, m \\
\hline
\end{tabular}




\begin{tabular}{|l||l|l|l|l|}
\hline \hline FR5 & 3 (bottom heat only) & 111 & 28 & 0.02 \\
\hline FR6 & 7 (four side heaters) & 148 & 80 & 0.26 \\
\hline FR6b & 7 (four side heaters) & 148 & 80 & 0.46 \\
\hline
\end{tabular}

\section{Calculation of Saturation}

The first step in the quantitative calculation of saturation is the normalization of the radiographs. Normalization corrects for small variations in equipment performance such as power output, x-ray energy, and detector efficiency, and is accomplished through the use of wedge-shaped aluminum standards (both stepped and continuous). After normalization, $\mathrm{x}$-ray attenuation through the standards is the same for all radiographs.

The equation that describes the absorption of $\mathrm{x}$-rays in a material, assuming a monochromatic source, is:

$$
\mathrm{dI} / \mathrm{I}=-\mu \rho d x
$$

where $I$ is the intensity, $\mu$ is the mass absorption coefficient, $\rho$ is the density, and $x$ is the thickness of the material through which the $\mathrm{x}$-rays pass. The integrated form of (1) is

$$
I=I_{0} \exp [-\mu \rho x]
$$

where $I_{0}$ is the intensity of the incident beam, and $I$ the intensity of the transmitted beam. For our work, we have the initial image (dry image) and all subsequent (more saturated) images. For the dry case,

$$
I_{d}=I_{o} \exp \left[-\left(\mu_{r} \rho_{r} x_{r}+2 \mu_{c} \rho_{c} x_{c}\right)\right]
$$

where the subscripts $\mathrm{c}$ and $\mathrm{r}$ represent the chamber and rock, respectively. For later, partially saturated images, we have

$$
\mathrm{I}_{\mathrm{Sw}}=\mathrm{I}_{\mathrm{o}} \exp \left[-\left(\mu_{\mathrm{r}} \rho_{\mathrm{r}} \mathrm{x}_{\mathrm{r}}+2 \mu_{\mathrm{c}} \rho_{\mathrm{c}} \mathrm{x}_{\mathrm{c}}+\mu_{\mathrm{l}} \rho_{1} \mathrm{x}_{1}\right)\right]
$$

where the subscript 1 represents the liquid that has imbibed into the pore space. We assume the pore space filled with air is negligible with respect to x-ray attenuation. Dividing (4) by (3) and solving for saturation yields

$$
S w=\frac{\ln \left(\frac{I_{x S w}}{I_{x d}}\right)}{-\left(\rho_{l} \mu_{l} x \phi\right)}
$$

This formulation differs from that of Tidwell and Glass (1994) in that there is no requirement to perform radiography of both the dry and the saturated medium; however, it is necessary to know the porosity of the sample and assume that when averaged over the thickness of the sample the porosity is uniform. The 
calculation of saturation will fail at the fracture (edge-on to x-rays, porosity not known), in anomalously high or low porosity regions, and in regions where KI crystals are deposited as a result of prolonged boiling.

Cores of tuff were prepared for the specific purpose of evaluating the above method. The cores were machined into right cylinders approximately $1.9 \mathrm{~cm}$ diameter and $2.3 \mathrm{~cm}$ length. Five cores of approximately the same porosity $(10.5+/-0.2 \%)$ were selected from a larger population. Radiographs were taken of the nominally dry cores $(<1.5 \% \mathrm{Sw})$, with the cylinder axis parallel to the x-rays for a thickness similar to that of the tuff thickness in the flow experiments. Sample saturations were measured gravimetrically immediately prior and subsequent to radiography of cores pre-saturated to known water contents (approximately $0.5,22,49,74$, and 81\%). During the radiography there was some water loss or gain, depending on whether or not samples were relatively dry or wet. Figure 3 shows the calculated saturation of each core as a function of normalized x-ray attenuation coefficient. The actual saturations are also shown. This plot demonstrates (1) that the saturation/attenuation coefficient relationship is linear, and (2) that the calculation of Sw using equation 5 above is fairly accurate. For the samples greater than $40 \%$ $\mathrm{Sw}$, the calculated $\mathrm{Sw}$ is between the two gravimetrically determined saturations. Therefore, the error in calculated $\mathrm{Sw}$ is smaller than the range of saturations measured before and after the radiography. For the two lower saturated samples, the calculated saturations are higher than the gravimetrically determined saturations. At the lowest saturation the error is $\sim 10 \% \mathrm{Sw}$.

\section{RESULTS AND DISCUSSION}

\section{Results of Previous Experiments}

A series of experiments similar to those described above was performed earlier on several samples under a variety of conditions (Roberts and Lin, 1996). Sample sizes and initial conditions may have been different, as well as the sample holder design. The general results of those experiments are described here briefly. These experiments included: (1) Fracture flow and imbibition with nominal normal stress on an unshimmed fracture $\left(23^{\circ} \mathrm{C}\right.$, sample initially dry, water ponded on top); (2) Fracture flow and imbibition with shims of 25 $\mu \mathrm{m}$ thickness placed in the fracture $\left(23^{\circ} \mathrm{C}\right.$, sample dried after (1), water ponded on top); (3) Dehydration of the sample after (2) under a thermal gradient created by imposing temperatures of $\sim 95^{\circ} \mathrm{C}$ at the bottom and $\sim 33^{\circ} \mathrm{C}$ at the top.

Imbibition occurred chiefly through the matrix for the unshimmed fracture experiment, and primarily horizontally from the fracture to the matrix during the shimmed fracture experiment. A roughly v-shaped wetting front was observed for the unshimmed case, and after more than 2017 hours of ponding, water still had not flowed the length of the fracture. During the shimmed fracture experiment, water flowed the fracture length after only $\sim 0.15$ hours. Different (lateral) imbibition rates were observed in different regions of the sample, demonstrating the heterogeneous properties of the rock. Enhanced imbibition appeared to be controlled by the presence of lithic fragments that contain small microfractures. A significant difference in the two series of experiments is that water imbibed laterally into the matrix (from the fracture) at a much higher rate when the fracture was shimmed open. For the shimmed experiment, after 1000 hours a large portion of the sample was highly saturated.

The dehydration experiment (3) began after no more imbibition into the matrix was observed (shimmed experiment, $>1200$ hours of imbibition). Dryout along the fracture was observed and was most pronounced between 4.5 and 23 hours after heating was initiated. At longer times dryout along the fracture was not apparent, and at times greater than $\sim 215$ hours the fracture was highly attenuating. Possible explanations include: (1) the fracture increased in saturation at times greater than 215 hours, or (2) evaporation of water continuously along the fracture resulted in the crystallization of salt (KI) that attenuates the X-rays. Another feature was the development of a horizontal band of high attenuation approximately $1.5-2 \mathrm{~cm}$ from the bottom of the sample. This band appeared initially at about 0.5 hours after heating, and became more pronounced with time. At about 25 hours after heating, two such bands were observed, again near the bottom of the sample. 


\section{Fracture Flow Under a Thermal Gradient}

Results for experiment FR5 are shown in Figure 4. These images are difference radiographs, and for the images shown here, darker shades indicate higher attenuation, and hence, indicate the presence of water. Figure 4a shows the progress of the wetting front in the matrix and the fracture after 1.7 hours since water was ponded on the top surface. The fracture is near the center of the image. The flow reached $\sim 13 \mathrm{~cm}$ down the fracture relatively quickly, and then stopped. The most likely reason for the stopped flow is the presence of a relatively high-porosity clast that is intersected by the fracture. As time progressed, this more porous region became more saturated until flow proceeded around or through the region. During this time there was significant lateral imbibition into the matrix from the fracture. The extent of this can be seen in Figure 4b, taken 73.5 hours after ponding. Figure $4 \mathrm{~b}$ still shows the highly attenuating spot where flow stopped and another highly attenuating region near the bottom of the sample. After flow continued past the highly porous region, the shape of the wetting front was less sharp and more rounded. This wetting front stopped $\sim 2.6 \mathrm{~cm}$ from the bottom of the sample. A very narrow neck of high attenuation extended downward from this section to the lowermost highly attenuating region at the bottom of the sample. In this sample the lowermost 1 to $2 \mathrm{~cm}$ are above boiling. Our interpretation is that the highly attenuating spot at the very bottom of the fracture is a region where KI crystals may have deposited because of continued boiling. For this experiment, liquid water never penetrated the entire fracture length. After nine days the heaters were turned off and water still did not flow through the fracture. Post-experiment examination of the fracture surface revealed small crystals in this region.

Figure 5 shows two difference images for experiment FR6 and FR6b. These two experiments were similar to FR5 except that FR6 was hotter, had less of a thermal gradient, and the column of water used to pond the sample was higher (refer to Table 1 for details). Figure 5a is an image of FR6 7.2 hours after ponding. Features indicated are rapid flow down the fracture that stops, development of a highly attenuating region, and the development of a narrow neck that is highly attenuating. Liquid water penetrated about $3 \mathrm{~cm}$ into the boiling region. The highly attenuating neck extending below the boiling region is unexplained. What is different about this experiment compared to FR5 is that flow continued down the length of the fracture after the heaters were turned off and the sample cooled. This is explained by either the increased head, or the lack of complete sealing of the fracture by crystal deposition.

Figure 5b shows an image of FR6b about 0.67 hours after flow was initiated. This sample had almost twice the head of FR6. The thermal gradient was the same, but in this case water flowed the entire length of the fracture within minutes and continued to flow through the boiling region. Thus we conclude that hydraulic head directly affects the distance liquid water can penetrate into the boiling region.

One interesting observation made for FR6 was the effect of fracture flow on the temperatures measured near the fracture. The ponded water was initially room temperature $\left(\sim 25^{\circ} \mathrm{C}\right)$. Thermocouples (TC) placed along the fracture $(\sim 3.7 \mathrm{~cm}$ away from fracture) measured temperature decreases as flow progressed through the fracture. Typically, temperature decreased rapidly (within $\sim 150$ seconds), reached a minimum, and rebounded to a subsequent value. If we disregard the top two thermocouples because of their closeness to the ponded water, we find that the largest temperature decrease was observed by TC9, which dropped by $~ 6$ ${ }^{\circ} \mathrm{C}$. The change in temperature decreased down the fracture until TC4 (the lowermost TC in the rock), which dropped by $\sim 1^{\circ} \mathrm{C}$. In general, the thermocouples reached a steady temperature within $1-2^{\circ} \mathrm{C}$ of the initial value after approximately 4500 seconds of flow. Theoretical work investigating infiltration of liquid fingers into hot rock (Phillips, 1996) predicts that the time to approach steady state temperatures is $\tau=1^{2} / \kappa$, where 1 is the penetration distance and $\kappa$ is the thermal diffusivity. For the current experiment this predicts a value of $\kappa$ of $\sim 1.5 \times 10^{-7} \mathrm{~m}^{2} \mathrm{~s}^{-1}$. Future work will include more carefully measured thermal histories in an attempt to determine how matrix saturation affects thermal properties.

\section{CONCLUSIONS}

We are able to visualize phenomena related to fracture flow and matrix imbibition during fracture flow experiments at a variety of conditions and to quantitatively calculate saturation within the matrix. Results 
indicate that under some conditions it is difficult for water to penetrate the region where temperatures are above boiling, but that water can penetrate this region upon cooling. Additional experiments where head was increased indicate penetration of the boiling region. Fracture flow stopped or slowed significantly when a region of higher porosity than the surrounding matrix was encountered. Heating a nearly saturated rock/fracture sample drove water out of the fracture on a very short time scale. These results provide important input needed for understanding coupled thermal-hydrological-chemical processes and models of repository-design-based performance. Directions for future work include measurement of temperature closer to the fracture and experiments with variable fracture aperture.

\section{ACKNOWLEDGMENTS}

D. Rikard, D. Ruddle, and D. Fletcher provided technical support. We thank Dan Schneberk for valuable discussions and ideas. This work was supported by the Yucca Mountain Site Characterization Project. Work performed under the auspices of the U.S.D.O.E by Lawrence Livermore National Laboratory under contract W-7405-ENG-48.

\section{REFERENCES}

Buscheck, T. A. and J. J. Nitao, (1992). The Impact of Thermal Loading on Repository Performance at Yucca Mountain, Proceedings Third International High-Level Radioactive Waste Management Conf., Las Vegas, NV, April 12-16. Also, UCRL-JC-109232, Lawrence Livermore National Laboratory, Livermore, CA.

Nitao, J. J. and T. A. Buscheck (1991). Infiltration Of a Liquid Front in an Unsaturated, Fractured Porous Medium, Water Resources Research, 27, 2099-2112.

Phillips, O. M. (1996). Infiltration of a Liquid Finger Down a Fracture into Superheated Rock, Water Resources Research, 32, 1665-1670.

Phillips, O. M. (1994). Liquid Infiltration Through the Boiling-Point Isotherm in a Desiccating Fractured Rock Matrix, Proceedings Fifth International High-Level Radioactive Waste Management Conf., Las Vegas, NV.

Roberts, J. J., and W. Lin (1996) X-ray Radiography of Fracture Flow and Matrix Imbibition, Proceedings Seventh International High-Level Radioactive Waste Management Conf., Las Vegas, NV, 89-91.

Tidwell, V. C. and R. J . Glass (1994). X-ray and Visible Light Transmission for Laboratory Measurement of Two-Dimensional Saturation Fields in Thin-Slab Systems, Water Resources Research, 30, 2873-2882.

Wilder, D. G., (1996). Near-Field and Altered-Zone Environment Report, Volume II, UCRL-LR-124998, Lawrence Livermore National Laboratory, Livermore, CA. 

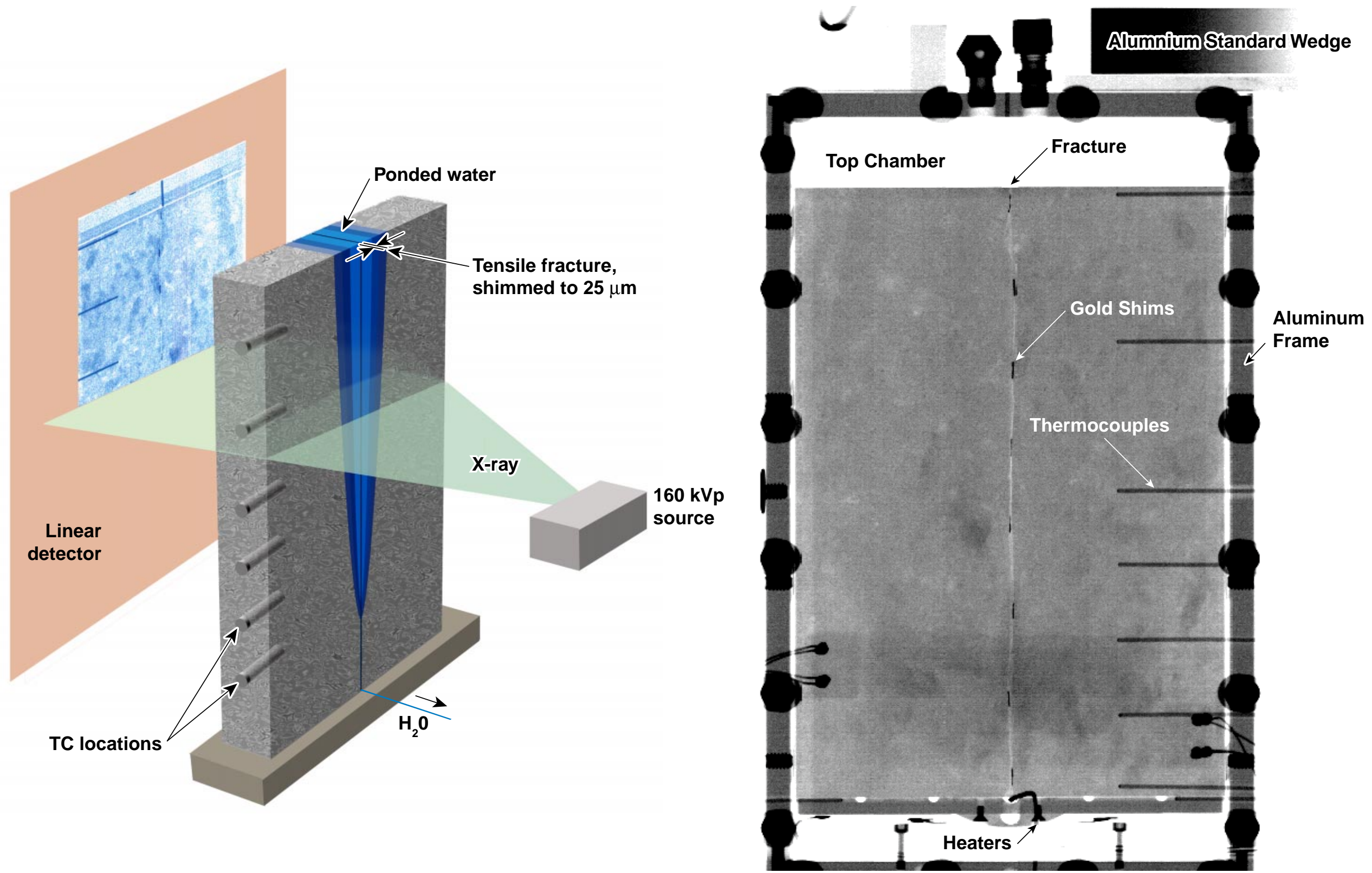

Figure 1. Schematic of $x$-ray radiograph system. Sample translates vertically through the $160 \mathrm{kVp}$ linear source. Detector stores digital data, line-by-line. One scan takes between one and two minutes, depending on sample height.

Figure 2. Radiograph of sample and assembly. Sample dimensions are $23 \times 15 \times 2.6 \mathrm{~cm}$. 


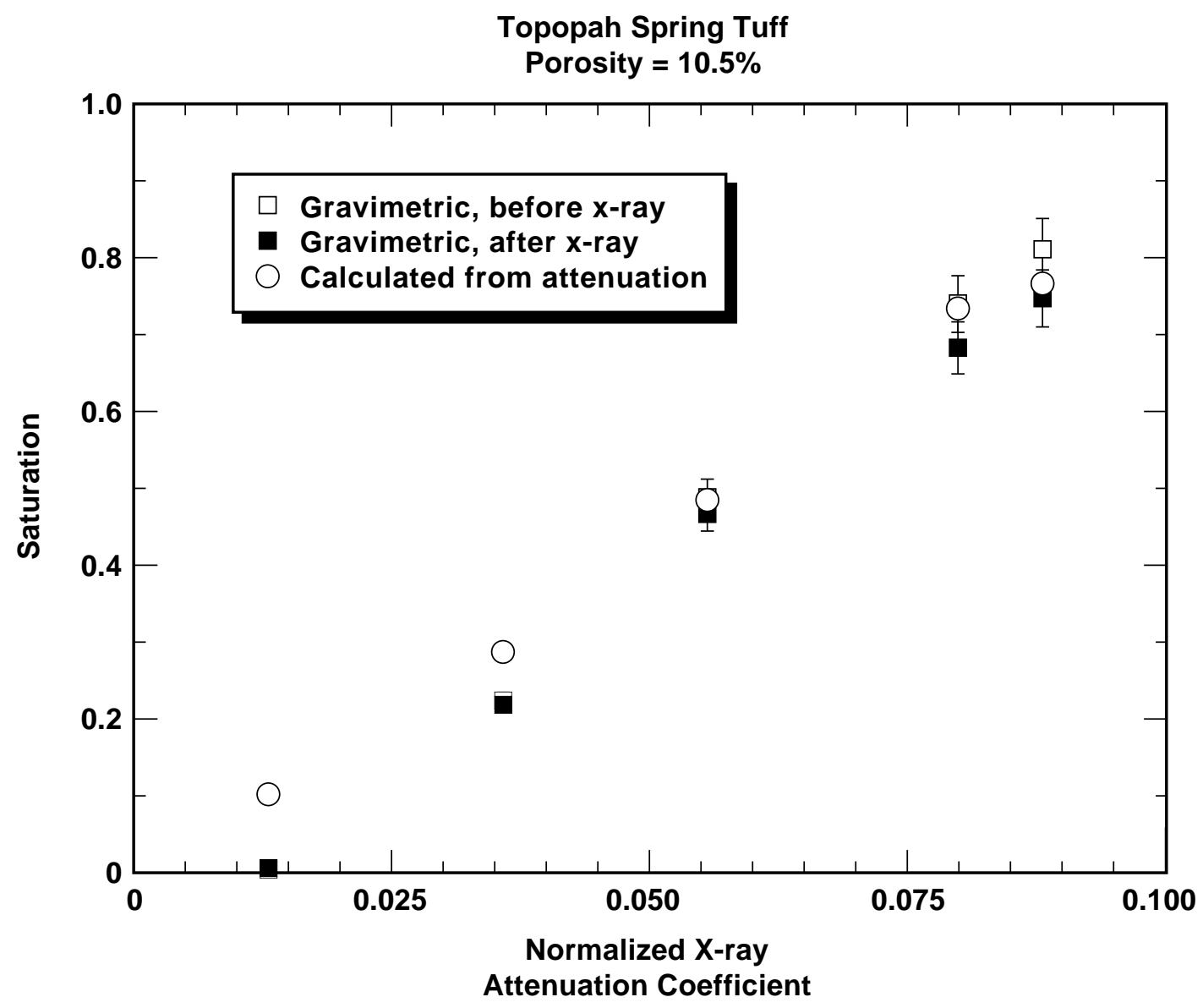

Figure 3. Saturation as a function of normalized $x$-ray attenuation coefficient for five samples of Topopah Spring tuff. The average porosity of the tuff is $10.5+/-0.1 \%$. Samples were prepared to specific saturations that were re-determined gravimetrically before and after radiography (open and filled squares). Open circles indicate saturation calculated from radiographs using Equation 5. 

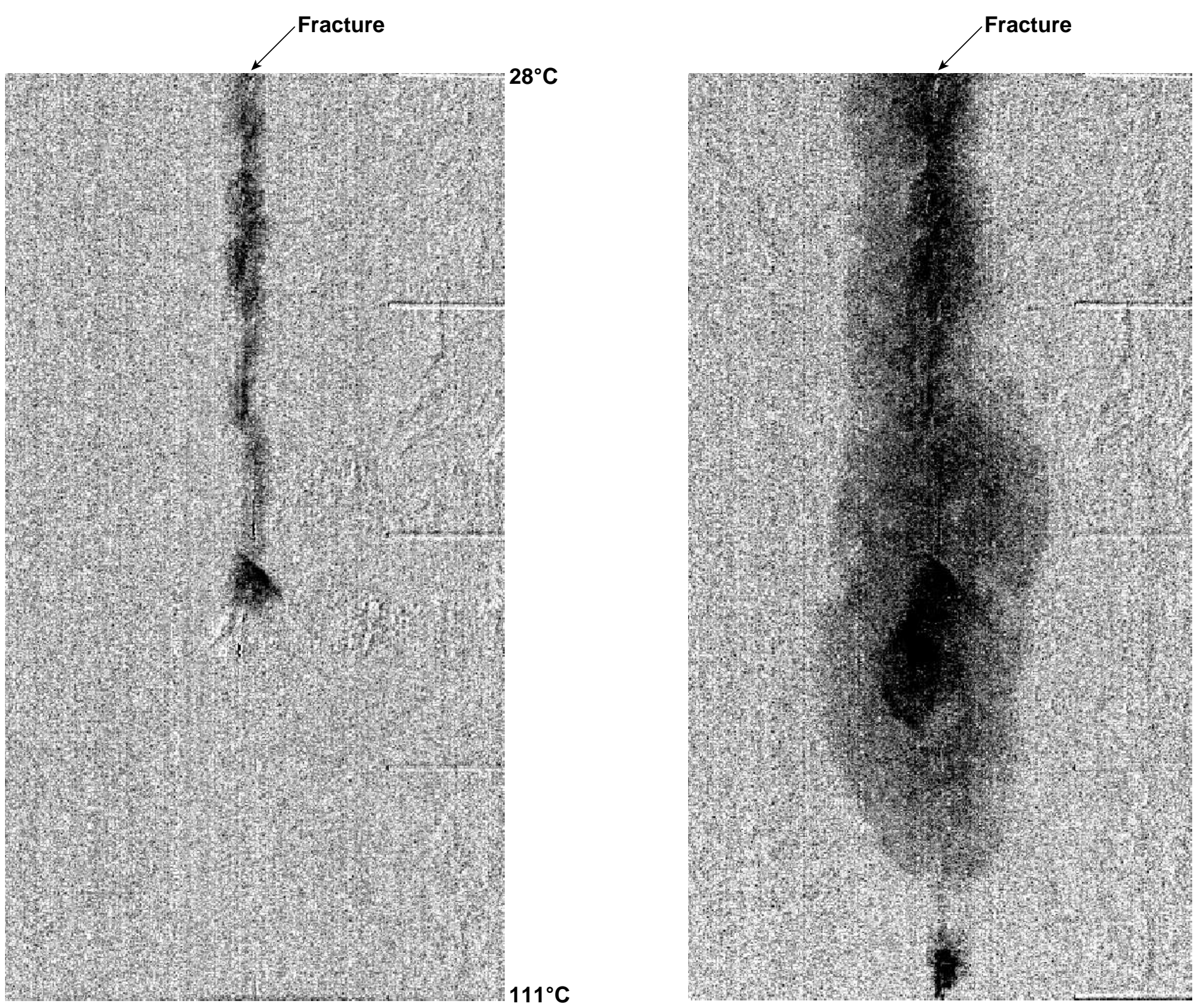

Figure 4. Difference radiographs of FR5. Darker shades indicate increased $x$-ray attenuation compared to the initial image, and hence, increased saturation. Images were taken 1.7 (a) and 73.5 (b) hours after flow was initiated. The first image shows a stoppage of flow along the fracture caused by the presence of a relatively porous region intersected by the fracture. The second image shows progression of the wetting front past the highly porous region to the boiling zone. See text for further discussion. 


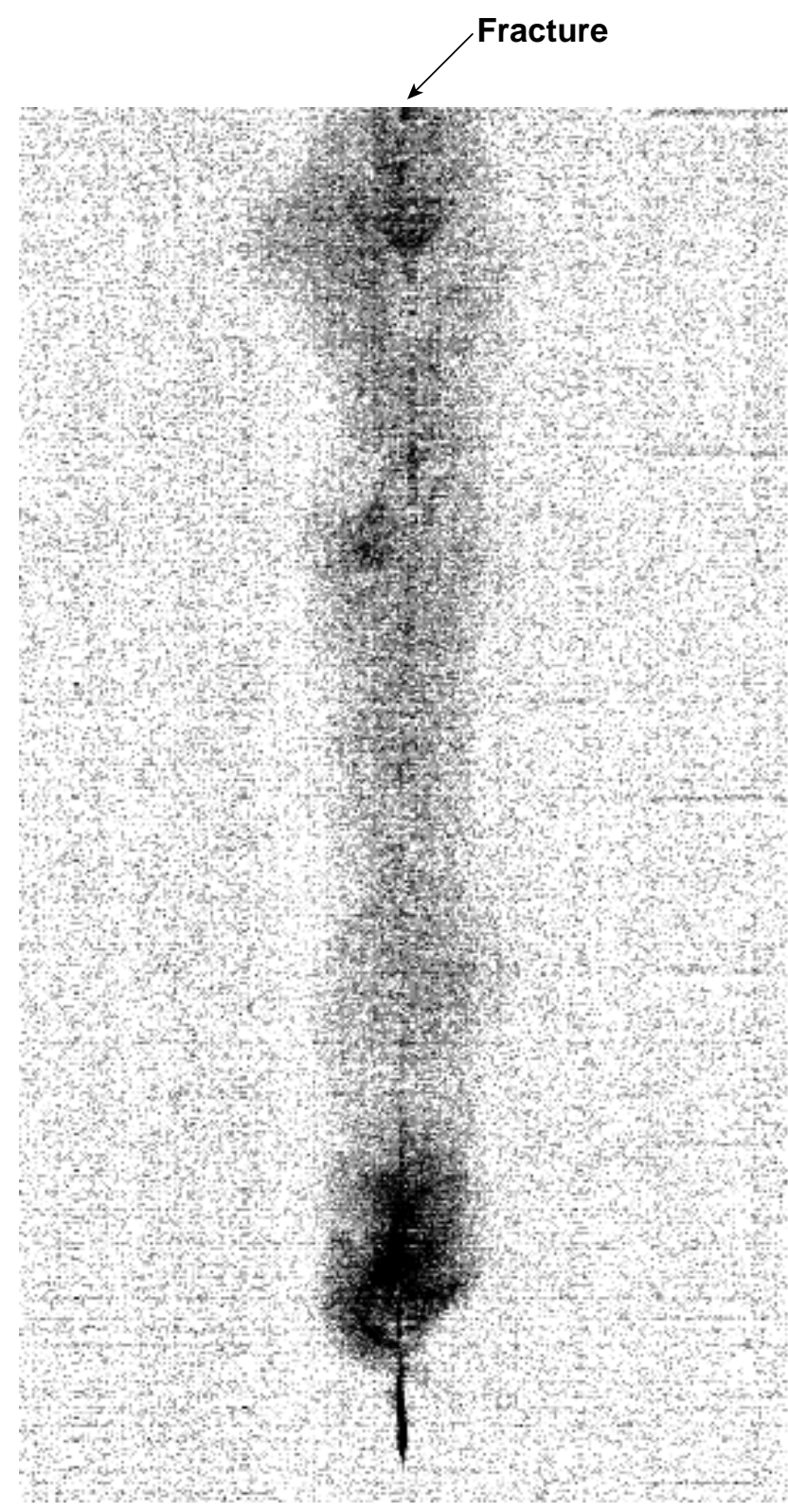

$80^{\circ} \mathrm{C}$

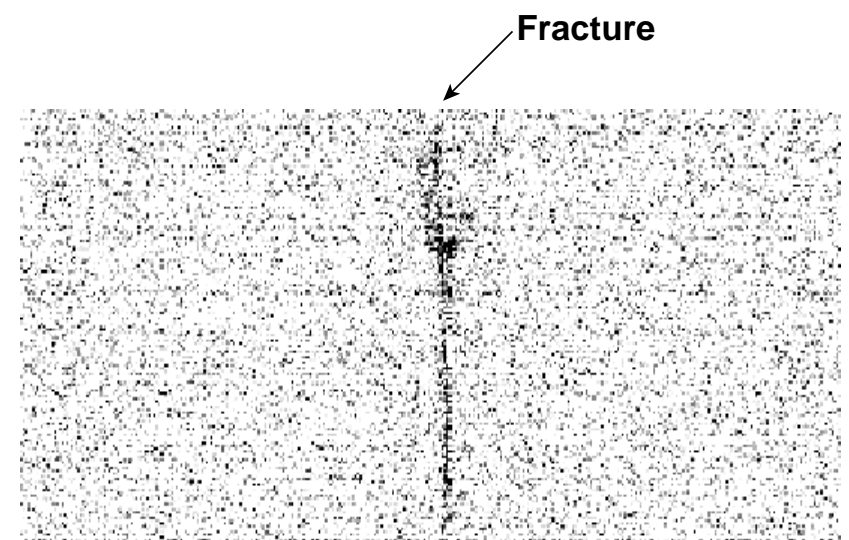

$85^{\circ} \mathrm{C}$

$93^{\circ} \mathrm{C}$

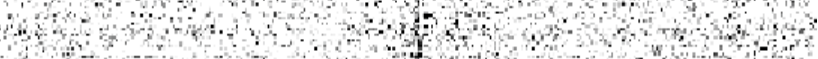

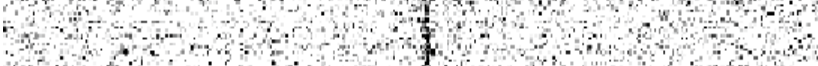

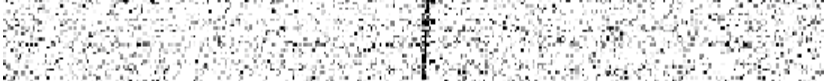

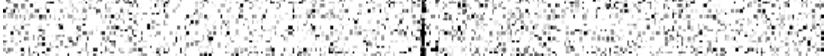

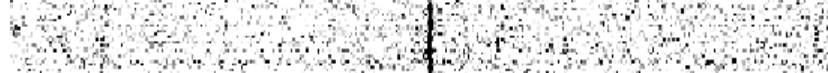

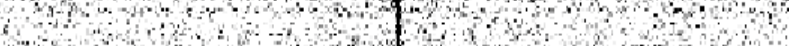

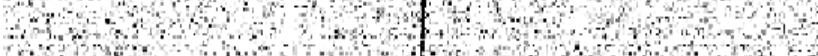

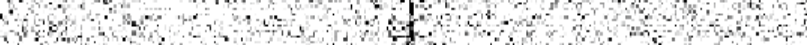

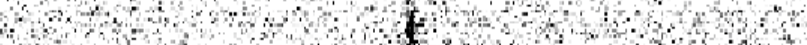

$98^{\circ} \mathrm{C}$

$103^{\circ} \mathrm{C}$

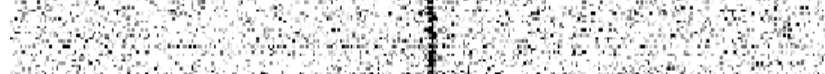

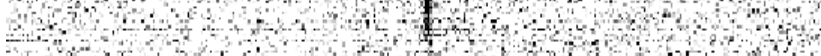

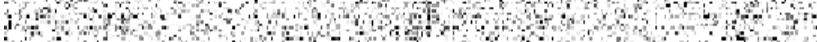

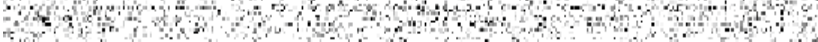

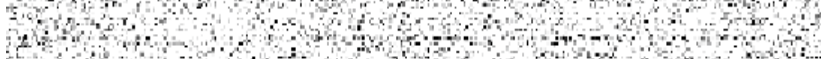

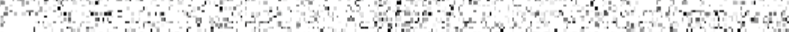

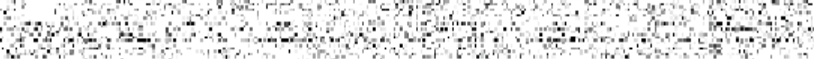

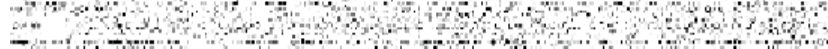

$111^{\circ} \mathrm{C}$

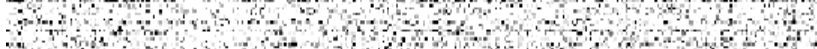

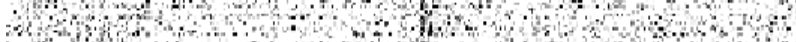

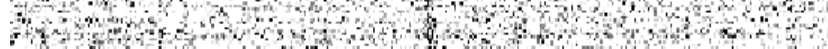

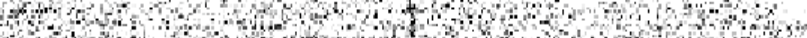

$148^{\circ} \mathrm{C}$

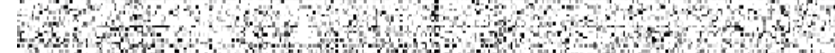

Figure 5. Difference images of FR6 (a) and FR6b (b), 7.2 and 0.67 hours after flow was initiated. Thermal gradient is indicated between the figures. The difference between these two experiments was the height of the water column, 0.26 and $0.46 \mathrm{~m}$, for FR6 and FR6b, respectively. The difference in head was large enough to force flow through the boiling region during FR6b. 


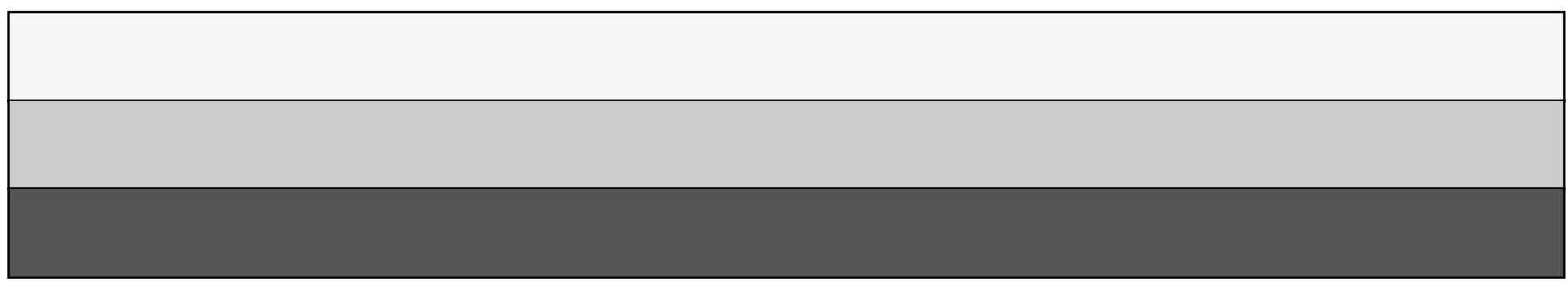

